\title{
Musical scales and brightness evaluations: Effects of pitch, direction, and scale mode
}

\section{WILLIAM G. COLLIER* AND TIMOTHY L. HUBBARD** *University of North Carolina at Pembroke \\ ** Texas Christian University}

\begin{abstract}
- Abstract
A common form of synesthesia and nonsynesthetic cross-modal matching involves an association of visual brightness and auditory frequency, and the form of this association was studied in nonsynesthetic observers who rated the perceived brightness of ascending and descending musical scales drawn from four modes (natural, melodic, and harmonic minor modes, and major modes [including both relative and parallel major scales]). The descending harmonic minor mode was rated as darker than the descending natural/melodic minor mode. Ascending minor and major modes were rated as brighter than descending minor and major modes. In addition, musical keys that started on a higher pitch were rated as brighter than musical keys that started on a lower pitch. No consistent differences in ratings of brightness were found between musically experienced and musically inexperienced participants. The data are consistent with previous findings and suggest that more global aspects of pitch height, pitch distance between subsequent notes, and pitch contour (i.e., the direction of pitch movement), rather than mode or key per se, influence ratings of the brightness of musical stimuli, and suggest recent use of "brightness" as a descriptor of or synonym solely for timbre may not be appropriate.
\end{abstract}

A small number of individuals who are presented with a stimulus in one modality report experiencing that stimulus in a different modality. Such an experience is typically referred to as synesthesia, and recent books reveal a growing interest on this topic (e.g., Baron-Cohen and Harrison, 1997; Cytowic, 2002; Harrison, 2001). The most common form of synesthesia involves individuals who experience visual sensations upon being presented with an auditory stimulus, and examples of such "colored hearing" have a long history of medical and psychological investigation (for review, see Marks, 1975). Typically, different vowel sounds may give rise to sensations of different hues, although there is often wide variability across individuals. However, one common pattern that is often found in auditory-visual synesthetic associations is that low auditory frequencies are associated with sensations of visual 
darkness or dimness, and high auditory frequencies are associated with sensations of visual brightness or lightness (Marks, 1975). Interestingly, similar associations between low auditory frequency and visual darkness and between high auditory frequency and visual brightness are found in non-synesthete individuals who are asked to select the auditory frequency that matches a gray surface (Marks, 1974) or select the gray surface that matches an auditory frequency (Hubbard, 1996).

The majority of research involving synesthesia-like correspondences between auditory frequency and visual brightness involve individuals who match a single visual brightness to a single auditory frequency (e.g., Marks, 1974). In one exception to this, Hubbard (1996) asked non-synesthete observers to choose which value of gray (from eleven equal-sized columns varying from white on one side to black on the other side) seemed to best fit a two-note melodic (i.e., sequential) musical interval. Observers chose lighter grays for intervals that ascended and darker grays for intervals that descended; interestingly, more extreme values were chosen for larger intervals (i.e., larger ascending intervals were matched with lighter visual stimuli than were smaller ascending intervals, larger descending intervals were matched with darker visual stimuli than were smaller descending intervals). One possible explanation for this pattern is that the lightness value chosen as the best match for a given melodic interval reflected the auditory frequency of the final note of the interval: the second note of a larger ascending interval was a higher auditory frequency than the second note of a smaller ascending interval, and the second note of a larger descending interval was a lower auditory frequency than the second note of smaller descending interval.

Research on auditory-visual synesthesia and synesthesia-like matching of auditory and visual stimuli is not limited to studies involving matching visual brightness with a single auditory frequency or a pair of auditory frequencies. Indeed, much of the initial research often involved presentation of musical excepts drawn from recordings or from live performance of orchestral compositions (e.g., Karwoski, Odbert and Osgood, 1942; Lehman, 1972). While perhaps offering some measure of ecological validity, such studies suffered from confounds in pitch direction, key, loudness, tempo, timbre, and a variety of other factors, therefore making it difficult to determine which elements of the musical structure were most salient in synesthesia or in synesthesia-like matching. The findings of Marks (1974) and Hubbard (1996) suggest that auditory frequency may determine which values of visual brightness a given auditory stimulus appears to best match, but musical pitch does not correspond to the single dimension of auditory frequency (Shepard, 1982). For example, Shepard's (1965) helical model of musical pitch involves the dimensions of pitch height (auditory frequency) and tone chroma (position of a note within the scale, and corresponding to the letter name of the pitch), and so it is possible that auditory-visual synesthesia and synesthesia-like matching of brightness and lightness with musical stimuli may be related to a non-frequency element of musical pitch such as tone chroma. 
Early research on the relationship of brightness to musical stimuli focused on the relationship between brightness and pitch. For example, Rich (1919) instructed participants to judge either the pitch difference or the brightness difference between two tones. Ratings of pitch and ratings of brightness were highly similar, thus suggesting that pitch and brightness are highly related or even the same, but the small number of subjects (4) and the possibility of demand characteristics (in the instructions, brighter was equated with lighter and duller with darker) preclude confidence in this conclusion. However, Boring and Stevens (1936) found that brightness ratings of single tones were influenced by timbre and by intensity as well as by auditory frequency, thus calling into question the similarity or equivalence of pitch and brightness. More recently, Marks (1982) presented experimental participants with lists of words that described lightness, sound, or light-sound metaphors. Ratings of pitch and ratings of brightness were highly correlated, leading Marks to suggest that pitch and brightness were similar or even identical. Marks (1987) found that discrimination of visual stimuli was faster and more accurate if an accompanying auditory stimulus was congruent with that visual stimulus (e.g., a dim visual stimulus accompanied by a low auditory frequency, a bright visual stimulus accompanied by high auditory frequency); although such a pattern is consistent with previously reported correlations between brightness and auditory pitch, it does not necessarily imply that brightness and auditory pitch are the same quality.

Some researchers have equated brightness and timbre and used the term "brightness" as a descriptor of timbre (e.g., Demany and Semal, 1993). For example, Wapnick and Freeman (1980) manipulated recorded clarinet tones using a seven band audio equalizer, and they created what four woodwind faculty members at a university agreed were "bright" or "dark" timbre versions of the same note. Similarly, Fung (1996) had doctoral music students rate characteristics of musical excerpts, and there was high agreement regarding whether each excerpt involved a "bright timbre" or a "dull timbre". In such studies, "brightness" was considered an auditory quality rather than a nonauditory (visual) dimension. In conceiving of brightness in this way, any possible synesthetic or cross-modal meaning of "brightness" appeared to be disregarded, and so the relevance of these findings to issues in synesthesia and synesthesia-like matching is less clear. Other researchers have reported evidence suggesting brightness and timbre should not be equated and that brightness is not an appropriate or useful descriptor of timbre. For example, Von Bismarck (1974) had experimental participants complete thirty semantic differential ratings for 35 different timbres. In a factor analysis of all the data, Von Bismarck found the strongest factor consisted of eight rating scales with high loadings; seven other rating scales (sharp-dull, hard-soft, loud-soft, angular-rounded, tense-relaxed, obtrusive-reserved, and unpleasant- 
pleasant) exhibited higher loadings than did bright-dark on this strongest factor ${ }^{1}$.

Collier and Hubbard (1998-2001) found that participants rated higher auditory frequencies as visually brighter and lower auditory frequencies as visually darker, but they also found that participants rated a series of tones at a faster tempo as brighter than a series of tones at a slower tempo, and that tempo interacted with pirch height and with pitch contour (i.e., whether pitch movement was ascending or descending) to influence ratings of brightness. Collier and Hubbard (1998-2001) interpreted "brightness" not as a descriptor of either pitch or timbre, but as a separate and more synesthesia-like (i.e., visual) quality. Such an interpretation is consistent with the possibility that nonfrequency and nontimbral aspects of music (e.g., tempo, contour, mode, etc.) may be related to brightness. Thus, it is possible that brightness may be (at least partially) related to other aspects of music. One such aspect involves the musical structure (i.e., the spacing and relationships between notes) resulting from different musical modes. In the experiments reported here, participants were presented with ascending and descending scales in different musical modes (for an overview of modes and scales, see Appendix A) and rated the brightness or darkness of those scales. In Experiment 1, the natural, harmonic, and melodic forms of the minor mode were presented; in Experiment 2, the relative major mode was presented, and in Experiment 3, the parallel major mode was presented.

\section{EXPERIMENT 1}

In this experiment, participants were presented with either ascending or descending minor scales on each trial, and the scales were in the natural, harmonic, or melodic mode. These minor musical modes differ in the size of the intervals between adjacent notes of the scales (see Table 1 and Appendix A). Counting the ascending and descending versions of the scales separately, there were five different types of scales (as delineated in music theory [e.g., see Kostka and Payne, 1995], the descending melodic is identical to the descending natural minor, and so to decrease the total number of trials, separate descending natural scales and descending melodic scales were not presented). Scales were presented in one of six different keys, and key was counterbalanced across trials. After participants listened to a scale, they rated that scale on one of five dimensions; the data for ratings of brightness reported here were made using a 7 -point rating system (with " 1 " as dark and "7" as bright). Based

(1) The structure of timbre space has also been conceptualized as being composed of three dimensions including log-rise time, spectral centroid, and degree of spectral variation (McAdams, Winsberg, Donnadieu, De Soete and Krimphoff, 1995); others have studied timbre by examining participants' verbalizations of the dissimilarity of timbres (Samoylenko, McAdams and Nosulenko, 1996); and others have studied the relationship between timbre and consonance (Sethares, 1993). 
on Hubbard (1996) and Collier and Hubbard (1998-2001), it could be predicted that ascending scales should be rated as brighter than descending scales. Additionally, differences in the spacing between adjacent notes in the different forms of the minor mode might influence how light or how dark different forms of the minor mode are judged to be.

Table 1

Examples of scales in the key of $C$ used in Experiments 1, 2, and 3

Tone Chroma

Chromatic scale*

$\begin{array}{lllllllllllll}C & C & D & E b & E & F & F & \text { G } & \text { Ab } & \text { A } & \text { Bb } & \text { B } & C^{\prime}\end{array}$

c Natural minor (ascending and descending)**

$\begin{array}{llllllllll}C & D & E b & F & G & A b & B b & & C^{\prime}\end{array}$

c Melodic minor (ascending)***

$\begin{array}{llllllllll}C & D & E b & F & \text { G } & \text { A } & \text { B } & \text { C' }\end{array}$

c Harmonic minor (ascending and descending)

$\begin{array}{llllllllll}C & D & E b & F & G & A b & B & & \text { B } & \text { C' }\end{array}$

Relative Eb major scale (ascending and descending)

$\begin{array}{llll}\mathrm{Eb} & \mathrm{F} & \mathrm{G} & \mathrm{Ab}\end{array}$

$\mathrm{Bb} \quad \mathrm{C}^{\prime} \quad \mathrm{D}^{\prime} \quad \mathrm{Eb}^{\prime}$

Parallel $C$ major scale (ascending and descending)
C
$\mathrm{D}$
E F
G
A
B C'

*There is a half-step interval between each tone in the chromatic scale.

** The intervals between the sequences of tones in each scale are true for any key within the mode. *** The descending form of the melodic minor scale is the same as the descending natural minor scale.

\section{METHOD}

- Participants. The participants in all experiments were undergraduates at Texas Christian University who received partial course credit in introductory or intermediate psychology courses. Participants were not selected for musical background or experience. Twenty-four undergraduates (12 males and 12 females) participated in Experiment 1.

- Apparatus. The auditory stimuli were generated by a Macintosh IIsi microcomputer and presented through headphones connected directly to the microcomputer. The rating scales were displayed on an Apple RGB color monitor connected to the microcomputer, and the computer recorded the participants' responses. The monitor was located approximately 60 centimeters from the listener. The distance of the monitor from the observer and the loudness of the auditory stimuli could be 
adjusted slightly to permit maximum comfort and confidence in responses. Room illumination was at normal levels and provided by overhead fluorescent fixtures that were built into the ceiling.

\section{- Stimuli.}

- Auditory scale stimuli. The auditory stimuli consisted of minor scales composed of eight sequential sine wave tones ${ }^{2}$. The scales were based on an equal-tempered tuning, and on each trial the scale was in one of six keys: $g, a, b, f, c \#, d \#^{3}$. These different keys were equally spaced around the circle of fifths, and over the course of the trials each key was presented equally often. The starting pitches for the ascending scales were drawn from the octave between C4 $(261.6 \mathrm{~Hz})$ and C5 $(523.2 \mathrm{~Hz})$, and the starting pitches for the descending scales were drawn from the octave between C5 $(523.2 \mathrm{~Hz})$ and $\mathrm{C} 6(1046.4 \mathrm{~Hz})$; this insured that ascending and descending scales covered the same range of auditory frequencies. The scales were based on one of five minor modes: ascending natural, descending natural/melodic, ascending harmonic, descending harmonic, ascending melodic. The scales were presented at a constant tempo, with each note presented for 750 milliseconds (i.e., the duration of a quarter note at a tempo of 90 beats per minute).

- Rating system. A Likert scale with the numbers 1 through 7 equally spaced across the screen was printed in the middle of the screen. Anchor terms were printed outside the 1 and outside the 7 , and for the ratings of brightness reported here the anchor terms were dark (1) and bright (7).

- Design. After the presentation of each scale, participants made a judgment about that scale, and there were five types of judgments: happy/sad, awkward/not awkward, bright/dark, fast/slow, and speeding up/slowing down. The order of judgments was determined randomly across all the trials. The focus in this report is on judgments of brightness/darkness. The data regarding judgments of happiness/ sadness and awkwardness were reported in Collier and Hubbard (2001), and the data regarding judgments of speed and tempo change will be reported elsewhere. Each participant received 150 trials [ 6 keys $\times 5$ modes (ascending natural, descending natural/melodic, ascending melodic, ascending harmonic, and descending harmonic) $x 5$ judgments] in a different random order.

(2) It might be objected that sine waves are not appropriately "musical". However, both sine waves and the sounds produced by conventional musical instruments are consistent with linearity, and a sine wave can be regarded as an approximation to the perceived fundamental frequency of a particular musical note (for discussion, see Pierce, 1999). Thus, the use of sine wave stimuli provides a starting point for a focus on pitch per se.

(3) By convention, the names of minor scales are denoted using lower case letters, and the names of major scales are denoted using upper case letters. 
- Procedure. Participants were tested individually, and they initiated each trial by pressing a designated key. A single ascending or descending musical scale was then immediately presented, and after the scale had been presented, a single rating scale was visually presented on the monitor. Participants entered their judgment directly via the keyboard and then initiated the next trial. Participants were given five practice trials at the beginning of the session, and the practice trials were drawn randomly from the experimental trials. After completing the experimental trials, each participant filled out a brief musical background questionnaire. The entire session lasted approximately 30 minutes.

\section{RESULTS}

The mean rating for each individual key in Experiment 1 is presented in Table 2.

\section{Table 2}

Mean ratings of brightness for minor keys in Experiment 1

\begin{tabular}{lllllll}
\hline & $\mathrm{b}$ & $\mathrm{a}$ & $\mathrm{g}$ & $\mathrm{f}$ & $\mathrm{d} \#$ & $\mathrm{c} \#$ \\
\hline Ascending natural minor & 5.08 & 4.79 & 4.25 & 3.96 & 4.21 & 3.04 \\
Ascending melodic minor & 5.29 & 4.71 & 4.75 & 4.42 & 3.63 & 4.00 \\
Ascending harmonic minor & 5.17 & 4.63 & 4.42 & 3.88 & 3.92 & 3.29 \\
Descending naturallmelodic minor & 4.04 & 4.25 & 3.96 & 3.38 & 3.29 & 2.71 \\
Descending harmonic minor & 4.04 & 4.13 & 3.38 & 3.13 & 2.96 & 2.50 \\
\hline
\end{tabular}

Note: All ratings were based on a 7-point scale with smaller numbers indicating darker and larger numbers indicating brighter.

- Preliminary analyses. A median split of the scores on the musical background questionnaire was used to classify participants as either musically inexperienced $(M=.13$, range $=0.0$ to 0.6 years $)$ or musically experienced $(M=2.97$, range $=0.8$ to 9.2 years). No effects of musical experience were found for ratings of brightness. The only effect of gender was that female participants $(M=3.71)$ rated the descending harmonic minor scale as brighter than did male participants $(M=3.00)$; $t(22)=2.24, p<.036$. Subsequent analyses collapsed over gender and experience factors with ratings of brightness analyzed in a within-subjects analyses of variance (ANOVAs).

- Across key analyses. Across key analyses collapsed across keys and examined effects of mode on the responses to each of the rating scales. Mode influenced ratings 
of brightness, $F(4,92)=15.98, p<.0001$, and several a priori comparisons were carried out:

(a) Ascending minor scales ( $M=4.3)$ were rated as brighter than descending minor scales $(M=3.48), F(1,23)=39.49, p<.0001$.

(b) Natural minor scales $(M=3.91)$ did not differ in rated brightness from harmonic minor scales $(M=3.79), F(1,23)=2.36, p<.138$.

(c) Ascending natural minor scales $(M=4.22)$ were rated as brighter than descending natural minor scales $(M=3.60), F(1,23)=11.31, p<.003$.

(d) Ascending harmonic minor scales $(M=4.22)$ were rated as brighter than descending harmonic minor scales $(M=3.35), F(1,23)=15.69, p<.001$.

(e) Ascending minor modes did not differ in rated brightness, $F(2,46)=2.16$, n.s.

(f) Descending minor modes were rated significantly differently from each other, $F(1,23)=5.59, p<.03$. The descending natural $/ \mathrm{melodic}$ minor mode $(M=3.60)$ was rated as brighter than the descending harmonic minor mode $(M=3.35)$.

- Individual key analyses. Given that musical composers and theorists have attributed different characteristics to individual keys (e.g., see Sachs, 1955), individual key analyses examined effects of key on the responses to each of the rating scales. Comparisons of individual keys within each of the modes were also carried out:

(a) Ascending natural minor keys were rated significantly different from each other, see Table $2[F(5,115)=11.74, p<.0001]$. Post hoc Tukey's HSD tests $(p<.05)$ of all pairwise comparisons revealed that the key of $c \#(M=3.04)$ was rated as darker than the keys of $\mathrm{d} \#(M=4.21), \mathrm{f}(M=3.96), \mathrm{g}(M=4.25)$, a $(M=4.79)$, and $\mathrm{b}(M=$ $5.08)$. In addition, the key of $\mathrm{b}(M=5.08)$ was rated as brighter than the keys of $\mathrm{f}(M=3.96)$ and $\mathrm{d} \#(M=4.21)$.

(b) Ascending melodic minor keys were rated significantly different from each other $[F(5,115)=6.12, p<.0001$, see Table 2]. Post hoc Tukey's HSD tests $(p<.05)$ of all pairwise comparisons revealed that the key of $d \#(M=3.63)$ was rated as darker than the keys of $\mathrm{g}(M=4.75), \mathrm{a}(M=4.71)$, and $\mathrm{b}(M=5.29)$. In addition, the key of $\mathrm{b}(M=5.29)$ was rated as brighter than the key of $c_{\#}(M=4.00)$.

(c) Descending natural/melodic minor keys were rated significantly different from each other $[F(5,115)=7.22, p<.0001$, see Table 2]. Post hoc Tukey's HSD tests $(p<.05)$ of all pairwise comparisons revealed that the key of $c \#(M=2.71)$ was rated as darker than the keys of $\mathrm{g}(M=3.96)$, a $(M=4.25)$, and $\mathrm{b}(M=4.04)$. In addition, the key of a $(M=4.25)$ was rated as brighter than the key of $\mathrm{d} \#(M=3.29)$.

(d) Ascending harmonic minor keys were rated significantly different from each other $[F(5,115)=9.51, p<.0001$, see Table 2]. Post hoc Tukey's HSD tests $(p<.05)$ of all pairwise comparisons revealed that the key of $c \#(M=3.29)$ was rated as darker than the keys of $\mathrm{g}(M=4.42)$, a $(M=4.63)$, and $\mathrm{b}(M=5.17)$. In addition, the key of b $(M=5.17)$ was rated as brighter than the keys of $\mathrm{f}(M=3.88)$ and $\mathrm{d} \#(M=3.92)$. (e) Descending harmonic minor keys were rated significantly different from each other $[F(5,115)=6.86, p<.0001$, see Table 2]. Post hoc Tukey's HSD tests $(p<.05)$ 
of all pairwise comparisons revealed that the key of $c \sharp(M=2.50)$ was rated as darker than the keys of a $(M=4.13)$ and $\mathrm{b}(M=4.04)$. In addition, the key of a $(M=4.13)$ was rated as brighter than the keys of $\mathrm{f}(M=3.13)$ and $\mathrm{d} \#(M=2.96)$. The key of $\mathrm{b}$ $(M=4.04)$ was rated as brighter than the key of $\mathrm{d} \#(M=2.96)$.

\section{DISCUSSION}

Regardless of minor mode, contour influenced ratings of brightness, as participants generally rated ascending scales as brighter than descending scales, and the only difference in brightness ratings between minor modes was that participants rated the descending harmonic minor mode as darker than the descending natural/melodic minor mode. Given that both the descending harmonic minor scale and the descending natural/melodic minor scale end with whole steps when descending from the supertonic to the tonic (i.e., the interval between the last two notes of each scale is the same), a difference in the size of the final interval of each descending scale cannot account for this pattern; however, there is a difference in the size of the first and second intervals (descending from the octave to the seventh scale degree/ subronic and from there to the sixth scale degree/submediant) of each descending scale (i.e., a half-step followed by one and a half-whole steps for the first two descending intervals of the descending harmonic minor mode, whereas the same intervals are both whole-steps in the descending natural/melodic minor mode; see Table 1 and Appendix A). The larger descending jump near the beginning of the descending harmonic minor mode may have resulted in that mode being rated as darker, and this would be consistent with Hubbard's (1996) finding that larger descending intervals were matched with darker visual stimuli. The hypothesis that the interval spacing between the first few notes of a scale influence ratings of brightness is also consistent with the failure to find any significant differences in ratings of brightness between the ascending minor modes, because the first four intervals between tones in all three ascending minor modes are the same.

Significant differences were found between the ratings of the individual musical keys. For ascending natural minor keys, the key of $\mathrm{c \#}$ was rated as darker than the keys of $d \#, f, g, a$, and $b$; and, the keys of $f$ and $d \#$ were rated as darker than the key of $b$. For ascending melodic minor keys, the key of $d \#$ was rated as darker than the keys of $\mathrm{g}$, $\mathrm{a}$, and $\mathrm{b}$; in addition, the key of $\mathrm{b}$ was rated as brighter than the key of $c \#$. For ascending harmonic minor keys, the key of $c \#$ was rated as darker than the keys of $\mathrm{g}$, a, and $\mathrm{b}$; and, the keys of $\mathrm{f}$ and $\mathrm{d \#}$ were rated as darker than the key of b. For descending harmonic minor keys, the key of $\mathrm{c \#}$ was rated as darker than the keys of $a$ and $b$; in addition, the keys of $f$ and $d \#$ were rated as darker than the key of $a$; and, the key of $d \#$ was rated as darker than the key of b. For descending natural/melodic keys, the key of $c \#$ was rated as darker than the keys of g, a, and b; in addition, the key of $d \#$ was rated as darker than the key of a. The differences between the individual musical keys are best explained in terms of pitch height: keys starting on higher pitches were rated as brighter than keys starting on lower pitches. This 
suggests brightness may be related to pitch height, and such a conclusion is consistent with previous findings.

The ratings for different minor modes, in conjunction with ratings for the different keys, suggest that neither mode nor musical key uniquely determines the brightness of musical stimuli. Rather, pitch height, contour, and the size of the intervals berween the first few tones of a scale appear to be the most important factors influencing ratings of brightness. It should also be pointed out that even though the sine wave timbre of the auditory frequencies remained constant throughout Experiment 1, the ratings of brightness varied; furthermore, differences in brightness ratings occurred with both high and low musically experienced participants. This supports the earlier suggestion that the term "brightness" should not be used solely as a descriptor of or synonym for timbre. Ratings of brightness as a function of pitch, although not identical, were very similar to ratings of happiness/ sadness as a function of pitch reported previously ( $c f$., Collier and Hubbard, 2001); more specifically, Collier and Hubbard (2001) found that participants rated ascending scales as happy and descending scales as sad, and this is consistent with a linking of happiness and brightness in previous studies (e.g., Collier and Hubbard, 1998-2001; Marks, 1996). Similarly, the lack of any effect of mode on ratings of brightness in Experiment 1 paralleled the lack of any effect of mode on ratings of happiness in Collier and Hubbard (2001).

\section{EXPERIMENT 2}

If the musical structure of a specific scale is important in determining the brightness of that scale, then it should be possible to observe differences in ratings of brightness when the key of an ascending or descending scale is held constant and the spacing between the elements of that scale are varied. Experiment 2 tested this hypothesis, as well as the generality of the findings from the three minor modes, by having participants rate the brightness of scales based on the relative major mode. The relative major mode contains musical scales that have the same key signature as scales in the minor modes, but in which the relative spacings of adjacent notes differs. In other words, scales in the relative major mode have the same key signature, but begin and end on different pitches, with the relative major mode beginning three half-steps above the minor mode (see Table 1 and Appendix A). If the spacing of pitches in a musical scale influences the brightness of that scale, then we would not expect the pattern of brightness ratings of relative major scales to resemble the pattern of brightness ratings of minor scales in Experiment 1. However, if the contour or the key of a musical scale influences the rated brightness of that scale, then we would expect the pattern of brightness ratings of relative major scales to resemble the pattern of brightness ratings of minor scales in Experiment 1. 
- Participants. Twenty-two participants (11 males and 11 females) from the same participant pool used in Experiment 1 were recruited, and none of the participants had been involved in Experiment 1.

- Apparatus. The apparatus was the same as in Experiment 1.

- Stimuli. The timbre, tempo, and duration of tones were the same as in Experiment 1. The scales either ascended or descended, and were relative major scales ( $B b, C, D$, $A b, E, F \#$ ) based on the minor keys ( $g, a, b, f, c \#, d \#)$ used in Experiment 1 . The rating scales were the same as in Experiment 1.

- Design. Each participant received 60 trials (6 keys $\mathrm{x} 2$ directions $\times 5$ ratings) in a different random order.

- Procedure. The procedure was the same as in Experiment 1.

\section{RESULTS}

- Preliminary analyses. As in Experiment 1, preliminary analyses using median splits of musical experience and gender were carried out. Musically inexperienced participants $(M=.53$, range $=0$ to 1 year $)$ and musically experienced participants ( $M=2.88$, range $=1$ to 5.3 years) differed only in that there was a trend for experienced participants $(M=4.56)$ to rate the descending scale as brighter than did inexperienced participants, $(M=3.85) ; t(20)=-1.87, p<.076$. No gender differences were found. Subsequent analyses collapsed over gender and experience factors with ratings of brightness analyzed in within-subjects analyses of variance (ANOVAs).

Table 3

Mean ratings of brightness for relative major keys in Experiment 2

\begin{tabular}{lllllll}
\hline & $\mathrm{Bb}$ & $\mathrm{C}$ & $\mathrm{D}$ & $\mathrm{Ab}$ & $\mathrm{E}$ & $\mathrm{F}$ \\
\hline Ascending relative major & 5.45 & 3.36 & 4.18 & 5.09 & 4.59 & 5.27 \\
Descending relative major & 5.14 & 2.82 & 4.00 & 4.50 & 3.73 & 4.50 \\
\hline
\end{tabular}

Note: All ratings were based on a 7-point scale with smaller numbers indicating darker and larger numbers indicating brighter.

- Across key analysis. As predicted, the ascending relative major scale was rated as brighter $(M=4.66)$ than the descending relative major scale $(M=4.2), F(1,21)=$ $4.84, \mathrm{p}<.039$. 
- Individual key analyses. The musical keys significantly differed from each other on ratings of brightness $[F(5,105)=18.27, p<.0001]$. Comparisons of individual keys within each of the directions for the relative major scale were also completed. The mean ratings for brightness of the relative major scale for each of the individual keys are listed in Table 3.

(a) Ascending relative major keys $[F(5,105)=11.44, p<.0001]$ were rated significantly different from each other. Post hoc Tukey's HSD tests $(p<.05)$ of all pairwise comparisons revealed that the key of $\mathrm{C}(M=3.36)$ was rated as darker than the keys of $\mathrm{E}(M=4.59), \mathrm{F}_{\#}(M=5.27), \mathrm{Ab}(M=5.09)$, and $\mathrm{Bb}(M=5.45)$. In addition, the keys of $\mathrm{F} \#(M=5.27)$ and $\mathrm{Bb}(M=5.45)$ were rated as brighter than the key of $\mathrm{D}(M=4.18)$.

(b) Descending relative major keys $[F(5,105)=11.99, p<.0001]$ were rated significantly different from each other. Post hoc Tukey's HSD tests $(p<.05)$ of all pairwise comparisons revealed that the key of $\mathrm{C}(M=2.82)$ was rated as darker than the keys of $\mathrm{D}(M=4.00), \mathrm{F} \#(M=4.50), \mathrm{Ab}(M=4.50)$, and $\mathrm{Bb}(M=5.14)$. In addition, the key of $\mathrm{Bb}(M=5.14)$ was rated as brighter than the keys of $\mathrm{D}(M=$ $4.00)$ and $\mathrm{E}(M=3.73)$.

\section{DISCUSSION}

Ratings of brightness were influenced by contour, with participants rating the ascending relative major scale as brighter than the descending relative major scale. This pattern is consistent with findings for minor mode scales in Experiment 1, suggesting that contour influences perceived brightness of a series of pitches. In addition, significant differences were found between the ratings of the individual musical keys within the relative major mode. For ascending relative major keys, the key of $C$ was rated as darker than the keys of $E, F \#, A b$, and $B b$; also, the key of $D$ was rated as darker than the keys of $F \#$ and $B b$. For descending relative major keys, the key of $C$ was rated as darker than the keys of $\mathrm{D}, \mathrm{F} \#, \mathrm{Ab}$, and $\mathrm{Bb}$; in addition, the keys of $\mathrm{D}$ and $\mathrm{E}$ were rated as darker than the key of $\mathrm{Bb}$. Because all the scales in Experiment 2 were from the same mode (i.e., all of the scales in Experiment 2 had the same interval sizes between the corresponding ordinal notes of each scale) the size of intervals between the notes cannot explain these differences in key. As in Experiment 1, the differences between the individual musical keys may be best explained in terms of pitch height: Keys starting at higher pitches were rated as brighter than keys starting at lower pitches.

\section{EXPERUMENT 3}

The musical scales in the relative major mode used in Experiment 2 had the same key signatures as the musical scales in the minor modes used in Experiment 1; thus, across Experiments 1 and 2 key signature was constant, but the starting and stopping (and intermediate) pitches of scales in the minor and relative major modes 
varied. As a consequence of varying the starting and stopping pitches, the scales used in Experiments 1 and 2 covered slightly different pitch ranges. Given that higher pitches are perceived as happier, brighter, faster, and as speeding up more than lower pitches (Collier and Hubbard, 1998-2001), it may be that the findings of Experiments 1 and 2 on contour were simply a result of pitch height. In order to more precisely test this notion, it is necessary to hold the starting and stopping pitches constant while varying the key signature. One way to do this would be to examine brightness ratings of ascending and descending scales in the parallel major mode. As has already been pointed out, scales in the relative major and minor modes begin and end on different notes while maintaining the same key signature. However, musical scales in the parallel major and minor modes begin and end on the same pitches, but differ in the sequence of intervals as a result of their different key signatures (see Table 1 and Appendix A). Accordingly, in Experiment 3, participants' perceptions of the perceived brightness for ascending and descending scales in the parallel major mode were measured.

\section{METHOD}

- Participants. Twenty-two participants (9 males and 13 females) from the same participant pool used in Experiments 1 and 2 were recruited, and none of the participants had been involved in Experiments 1 or 2.

- Apparatus. The apparatus was the same as in Experiments 1 and 2.

- Stimuli. The timbre, tempo, and duration of tones were the same as in Experiments 1 and 2. The scales either ascended or descended, and were parallel

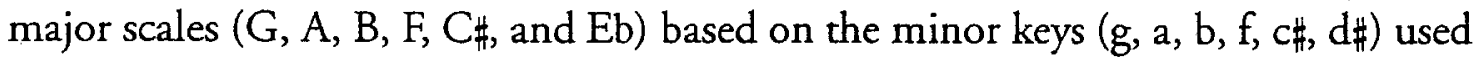
in Experiment 1. The rating scales were the same as in Experiments 1 and 2.

- Design. Each participant received 60 trials (6 keys x 2 directions $\times 5$ ratings) in a different random order.

- Procedure. The procedure was the same as in Experiments 1 and 2.

\section{RESULTS}

- Preliminary analyses. As in Experiments 1 and 2, preliminary analyses using median splits of musical experience and gender were carried out. Musically inexperienced participants ( $M=0.44$, range $=0$ to 1 year) and musically experienced participants ( $M=2.73$, range $=1.2$ to 4.8 years) differed only in that there was a trend for experienced participants $(M=4.86)$ to rate the ascending scale as brighter than did inexperienced participants, $(M=4.23) ; t(20)=-1.96, p<.064$. No effects of gender were found. Subsequent analyses collapsed over gender and experience factors with brightness ratings analyzed in within-subjects analyses of variance (ANOVAs). 
Table 4

Mean ratings of brightness for parallel major keys in Experiment 3

\begin{tabular}{lllllll}
\hline & & \multicolumn{7}{c}{ Key } & F & C\# \\
\hline Ascending parallel major & 5.14 & 5.33 & 4.71 & 4.43 & 4.05 & 3.67 \\
Descending parallel major & 4.71 & 4.24 & 3.81 & 3.52 & 3.10 & 2.43 \\
\hline
\end{tabular}

Note: All ratings were based on a 7-point scale with smaller numbers indicating darker and larger numbers indicating brighter.

- Across key analysis. As predicted, the ascending parallel major scale was rated as brighter $(M=4.55)$ than the descending parallel major scale $(M=3.63), F(1,21)=$ $34.13, p<.0001$.

- Individual key analyses. The musical keys significantly differed from each other on ratings of brightness $[F(5,100)=15.19, p<.0001]$. Comparisons of individual keys within each of the directions for the parallel major scale were also completed. The mean ratings for brightness of the parallel major scale for each of the individual keys are listed in Table 4.

(a) Ascending parallel major keys $[F(5,100)=7.15, p<.0001]$ were rated significantly different from each other. Post hoc Tukey's HSD tests $(p<.05)$ of all pairwise comparisons revealed that the key of $C_{\#}(M=3.67)$ was rated as darker than the keys of $\mathrm{G}(M=4.71), \mathrm{A}(M=5.33)$, and $\mathrm{B}(M=5.14)$. In addition, the keys of $\mathrm{B}(M=5.14)$ and $\mathrm{A}(M=5.33)$ were rated as brighter than the key of $\mathrm{Eb}(M=4.05)$. (b) Descending parallel major keys $[F(5,100)=8.68, p<.0001]$ were rated significantly different from each other. Post hoc Tukey's HSD tests $(p<.05)$ of all pairwise comparisons revealed that the key of $C_{\sharp}(M=2.43)$ was rated as darker than the keys of $\mathrm{G}(M=3.81), \mathrm{A}(M=4.24)$, and $\mathrm{B}(M=4.71)$. In addition, the keys of $\mathrm{B}(M=4.71)$ and $\mathrm{A}(M=4.24)$ were rated as brighter than the key of $\mathrm{Eb}(M=3.10)$. The key of $\mathrm{B}(M=4.71)$ was also rated brighter than the key of $\mathrm{F}(M=3.52)$.

\section{DISCUSSION}

Ratings of brightness were influenced by contour, with participants rating the ascending parallel major scale as brighter than the descending parallel major scale. This pattern is consistent with the findings for the minor mode scales observed in Experiment 1 and the relative major mode scales observed in Experiment 2. Significant differences were also found between the individual musical keys of the parallel major mode. For ascending parallel major keys, the key of $\mathrm{C} \#$ was rated as darker than the keys of $G, A$, and $B$; and, the key of Eb was rated as darker than the keys of $B$ and $A$. For descending parallel major keys, the key of $C \#$ was rated 
as darker than the keys of $G, A$, and $B$; in addition, the key of $E b$ was rated as darker than the keys of $B$ and $A$; and, the key of $F$ was rated as darker than the key of B. Once again, the differences are best explained in terms of pitch height, with keys starting on a higher pitch rated as brighter than keys starting on a lower pitch.

\section{GENERAL DISCUSSION}

Pitch height and contour influenced participants' ratings of the brightness of ascending and descending major and minor mode scales. In addition, the size of the intervals between the initial pitches of each scale may have influenced participants' ratings of brightness, as the descending harmonic minor mode (with a larger interval near the beginning) was rated as darker than the descending natural/melodic minor mode (with a smaller interval near the beginning). Even though Experiments 1, 2, and 3 clearly show that the direction and magnitude of pitch change influences brightness ratings (e.g., see also Hubbard, 1996), a consistent mapping of brightness and pitch may also be found if pitch height remains constant (e.g., Marks, 1974), and so it may be that effects of contour simply modulate this more general mapping. Comparison of the data from Experiments 1, 2, and 3 does not suggest the existence of any differences in rated brightness between minor and major modes; however, minor and major modes were not directly compared, and so the possibility of differences in brightness between minor and major modes cannot be conclusively ruled out. Also, there were no consistent differences in brightness ratings given by musically experienced or musically inexperienced participants, and this suggests associations of brightness with pitch or with key may be relatively low-level or direct and not relatively high-level or mediated or otherwise dependent upon extensive knowledge or cognitive processing.

The data of Experiments 1, 2, and 3 suggest that pitch and brightness are different qualities. This conclusion is at odds with previous research that suggested pitch and brightness were identical (e.g., Marks, 1982), but is consistent with research suggesting pitch and brightness are separable dimensions (e.g., Boring and Stevens, 1936). The data of Experiments 1, 2, and 3 also suggest that timbre and brightness are different qualities. This conclusion is at odds with previous research that considered "brightness" as a descriptor of timbre (e.g., Demany and Semal, 1993; Fung, 1996; Wapnick and Freeman, 1980), but is consistent with recent findings by Warrier and Zatorre (2002) that the influence of timbre on judgments of pitch diminished as the tonal structure of the stimuli increased: If "brightness" is the same phenomenological quality as timbre, and if the influence of timbre on pitch decreases as tonal (musical) structure increases, then we should not have observed consistent influences of pitch height on ratings of brightness for the highly 
tonal stimuli in Experiments 1, 2, and 3. In other words, there was a high level of tonal structure in the musical scale stimuli used in Experiments 1, 2, and 3, and given that timbre was constant across all of the stimuli, we would not have expected to find any differences in brightness ratings if brightness was equivalent to timbre or a descriptor of timbre.

The data of Experiments 1, 2, and 3 provide a useful and necessary balance between previous studies that presented rich and complex stimuli such as orchestral excerpts (e.g., Karwoski et al., 1942; Lehman, 1972) and studies that presented isolated tones or pairs of tones (e.g., Hubbard, 1996; Marks, 1974). Given that presentation of a musical scale results in activation of musical schemata (e.g., see Krumhansl, 1990), the use of musical scales as stimuli in Experiments 1, 2, and 3 encouraged the activation of musical schemata while still affording precise experimental control. Although the data of Experiments 1, 2, and 3 clearly demonstrated relationships of pitch height, contour, and interval sizes within an auditory stimulus to the rated brightness of that auditory stimulus, the lack of an effect of musical mode on brightness ratings is consistent with the possibility that brightness may not be related as much to music per se as to audition more generally. If we postulate that musical schemata involve relatively higher levels of cognition than does a more general (and nonmusical) recognition of auditory frequency, then the notion that brightness is related to audition more generally is consistent with the hypothesis mentioned earlier that connections of brigheness with auditory frequency or with key may be relatively low-level and direct rather than high-level or mediated.

Overall, Experiments 1, 2, and 3 clearly demonstrate that brightness is not identical with pitch or with timbre, although ratings of brightness were influenced by pitch height and by musical key. There is a clear relationship between pitch and contour in a musical stimulus and the rated brightness of that musical stimulus. This may indicate a possible synesthetic meaning for brightness, with higher pitches and ascending contours associated with greater brightness than are lower pitches and descending contours. Furthermore, the patterns of rated brightness reported here are consistent with those of Collier and Hubbard (1998-2001) that higher pitch, faster tempo, or ascending tones are also rated as happier, brighter, faster, and as speeding up more than lower pitch, slower tempo, or descending tones. Future studies should examine similarities and differences between synesthesia-like ratings and timbre ratings of auditory stimuli. Just as using pitch stimuli revealed differences not revealed by verbal sound terms in Marks (1982), presenting lightness stimuli rather than just a verbal rating scale of lightness terms might reveal differences not revealed by verbal ratings in Experiments 1, 2, and 3. Therefore, replicating these findings with stimuli that vary in brightness and with a visual rating system (e.g., as in Hubbard, 1996) should help clarify the extent to which "brightness" overlaps with auditory qualities or is more of a synesthetic-like quality. Further exploration of this relationship may provide more insight into the 
nature of music cognition, auditory representation, synesthesia, and synesthesialike matching 4 .

(4) The authors thank Andrzej Rakowski and an anonymous reviewer for comments on a previous draft of the manuscript.

Portions of these data were presented at the 1998 Joint Western Psychological Association-Rocky Mountain Psychological Association Convention.

Address for correspondence:

William G. Collier, Ph.D.

Department of Psychology and Counseling

The University of North Carolina at Pembroke

P.O. Box 1510

Pembroke, NC 28372-1510

USA

e-mail: william.collier@uncp.edu 


\section{- References}

Baron-Cohen, S., \& Harrison, J. E. (1997). Synaesthesia: Classic and contemporary readings. Cambridge, MA.: Blackwell Publishers.

Boring, E. G., \& Stevens, S. S. (1936). The nature of tonal brightness. Proceedings of the National Academy of Sciences of the United States of America, 22, 514-21.

Collier, W. G., \& Hubbard, T. L. (1998-2001). Judgments of happiness, brightness, speed and tempo change of auditory stimuli varying in pitch and tempo. Psychomusicology, 17, 3655.

Collier, W. G., \& Hubbard, T. L. (2001). Musical scales and evaluations of happiness and awkwardness: Effects of pitch, direction, and scale mode. American Journal of Psychology, 114, 355-75.

Cytowic, R. E. (2002). Synesthesia: A union of the senses. Cambridge, MA: The MIT Press.

Demany, L., \& Semal, C. (1993). Pitch versus brightness of timbre: Detecting combined shifts in fundamental and formant frequency. Music Perception, 11, 1-14.

Fung, C. V. (1996). Musicians' and nonmusicians' preferences for world musics: Relation to musical characteristics and familiarity. Journal of Research in Music Education, 44, 60-83.

Harrison, J. E. (2001). Synaesthesia: The strangest thing. New York: Oxford University Press.

Hubbard, T. L. (1996). Synesthesia-like mapping of lightness, pitch, and melodic interval. American Journal of Psychology, 109, 219-38.

Karwoski, T. F., Odbert, H. S., \& Osgood, C. E. (1942). Studies in synesthetic thinking: II. The roles of form in visual response to music. Journal of General Psychology, 26, 199-222.

Kostka, S., \& Payne, D. (1995). Tonal harmony with an introduction to Twentieth-century music (3rd ed.). New York: McGraw-Hill, Inc.

Krumhansl, C. L. (1990). Cognitive foundations of musical pitch. New York: Oxford University Press.

Lehman, R. S. (1972). A multivariate model of synesthesia. Multivariate Behavioral Research, 7 , 403-39.

Marks, L. E. (1974). On associations of light and sound: The mediation of brightness, pitch, and loudness. American Journal of Psychology, 87, 173-88.

Marks, L. E. (1975). On colored-hearing synesthesia: Cross-modal translations of sensory dimensions. Psychological Bulletin, 82, 303-31.

Marks, L. E. (1982). Bright sneezes and dark coughs, loud sunlight and soft moonlight. Journal of Experimental Psychology: Human Perception and Performance, 8, 177-93.

Marks, L. E. (1987). On cross-modal similarity: Auditory-visual interactions in speeded discrimination. Journal of Experimental Psychology: Human Perception and Performance, 13, 384-94.

Marks, L. E. (1996). On perceptual metaphors. Metaphor and Symboh 11, 39-66.

McAdams, S., Winsberg, S., Donnadieu, S., De Soete, G., \& Krimphoff, J. (1995). Perceptual scaling of synthesized musical timbres: Common dimensions, specificities, and latent subject classes. Psychological Research, 58, 177-92.

Pierce, J. (1999). Sound waves and sine waves. In P. R. Cook (ed.), Music, cognition, and computerized sound: An introduction to psychoacoustics (pp. 37-56). Cambridge, MA.: The MIT Press.

Rich, G. J. (1919). A study of tonal attributes. American Journal of Psychology, 30, 121-64. 
Sachs, C. (1955). Our musical heritage: A short history of music. Englewood Cliffs, NJ: Prentice Hall.

Samoylenko, E., McAdams, S., \& Nosulenko, V. (1996). Systematic analysis of verbalizations produced in comparing musical timbres. International Journal of Psychology, 31, 255-78.

Sethares, W. A. (1993). Local consonance and the relationship between timbre and scale. Journal of the Acoustical Society of America, 94, 1218-28.

Shepard, R. N. (1965). Approximation to uniform gradients of generalization by monotone transformations of scale. In D. I. Mostofsky (ed.), Stimulus generalization (pp. 94-110). Stanford, CA: Stanford University Press.

Shepard, R. N. (1982). Structural representations of musical pitch. In D. Deutsch (ed.), The psychology of music (pp. 343-90). New York: Academic Press.

Wapnick, J., \& Freeman, P. (1980). Effects of dark-bright timbral variation on the perception of flatness and sharpness. Journal of Research in Music Education, 28, 176-84.

Warrier, C. M., \& Zatorre, R. J. (2002). Influence of tonal context and timbral variation on perception of pitch. Perception \& Psychophysics, 64, 198-207.

Von Bismarck, G. (1974). Timbre of steady sounds: A factorial investigation of its verbal attributes. Acustica, 30, 146-59. 
A mode defines a particular relationship between a collection of tones. This relationship involves the sizes of the spacing between different tones, and different modes use different spacings. Differences between modes can be most easily illustrated in a consideration of different types of scales. A scale is a sequence of ordered (ascending or descending) tones, and a scale usually spans a distance of one octave. A chromatic scale contains all 13 tones that span an octave. Scales in different modes use different subsets of 8 of those 13 tones, and by using different subsets of tones the spacing between adjacent ordinal members of different modes will vary. For example, scales in the natural minor mode have a whole step between the first and second notes of the scale (i.e., the first two notes correspond to the first and third elements of a chromatic scale), but a half step between the second and third notes (i.e., the second and third notes correspond to the third and fourth elements of the chromatic scale). In contrast, scales in the major mode have a whole step between the first and second notes of the scale and also between the second and third notes of the scale (i.e., the first, second, and third notes correspond to the first, third, and fifth elements of a chromatic scale). Thus, one of the differences between scales in the natural minor mode and scales in the major mode is that distance between the second and third pitches in the major mode is twice as large as the distance between the second and third pitches in the natural minor mode. The use of the descriptors relative and parallel to describe the major mode reflects the relationship of those particular major scales to the scales in the minor modes. All major scales, whether "relative" or "parallel" share the same modal structure. The term "relative" refers to those major scales that share the same key signature as scales in the minor modes (although these major scales start on a different pitch three halfsteps above the minor modes), and the term "parallel" refers to those major scales that start and stop on the same pitch as scales in the minor modes (although these major scales will have a different key). Other differences between the modes are shown in Table A1.

Wirhin a given mode, the starting pitch for a scale may be any of the 13 pitches in a chromatic scale, and scales that start on different starting pitches are said to be in different keys. Because there are 12 unique starting pitches (the last note that completes the octave "repeats" the tone chroma of first note, and so is not unique), there are 12 different keys within each mode, and the name of the key of a given scale corresponds to the tone chroma of the starting pitch of that scale. All scales within a given mode share the same spacing of pitches within each scale regardless of key, even though the scale may begin on a different pitch (e.g., in every major scale, there will be a whole step difference between the first and second notes and also between the second and third notes). Thus, scales in different keys within a given mode all preserve the spacing and the musical structure of that mode even though scales in different keys may use different pitches (e.g., a musical composition 
in key of $\mathrm{C}$ major typically does not include a $\mathrm{F}$, and a musical composition in the key of $\mathrm{F} \#$ major typically does not include a $\mathrm{C}$, but musical compositions in $\mathrm{C}$ major and in $\mathrm{F} \#$ major would both clearly be in the major mode, and a composition in one of those keys could easily be transposed into the other key without any loss of structural information or distortion of note spacing [assuming an equal tempered tuning]). This is relevant to the experiments reported here because use of scales in different keys within a given mode allows a separation of effects of pitch height (i.e., differences between keys) from effects of mode.

\section{Table A1}

\section{The structure of different musical modes*}

\section{Mode Structures}

Chromatic scale**:

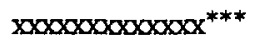

Natural minor mode (ascending and descending):

$x_{-} x x_{2} x_{2} x_{2} x_{2} x_{-} x$

Melodic minor mode (ascending):

$x_{-} x_{-} x_{-} x_{-} x_{-} x x$

Harmonic minor mode (ascending and descending):

$x_{-} x_{-} x_{-} x_{2} x_{-} \mathrm{xx}$

Major mode (ascending and descending):

$x \_x \_x x \_x \_x \_x x$

*Ascending scales in each mode begin on the left and continue to the right, whereas descending scales start on the right and continue to the left.

** There is a half-step interval between each tone in the chromatic scale.

***Notes are indicated by $X$ and intervals by . 
- Escalas musicales y evaluación de la brillantez: efectos de altura, dirección y modo de la escala

Una forma común de sinestesia y cruce modal no sinestésico supone la asociación de brillantez visual y frecuencia auditiva, y la forma de esta asociación fue estudiada en observadores no sinestésicos, que valoraban la brillantez de escalas musicales ascendentes y descendentes de cuatro tipos (escalas menores natural, melódica y harmónica menor, y modo mayor [incluyendo las escalas relativa y paralela). El modo harmónico menor descendente era valorado como más oscuro que el modo natural/melódico menor descendente. Los modos menores y mayores ascendentes eran valorados como más brillantes que esos mismos descendentes. Además, las tonalidades que comenzaban sobre una nota más aguda eran valoradas como más brillantes que las que comenzaban sobre una nota más grave. No se encontraron diferencias significativas en las valoraciones de brillantez entre los participantes experimentados musicalmente y los no experimentados. Los datos son coincidentes con resultados previos y sugieren que aspectos globales como la altura, la distancia entre notas seguidas y el perfil de las alturas (por ejemplo, la dirección del movimiento de alturas), en lugar del modo o la tonalidad en si mismas, influyen en las valoraciones de la brillantez de los estímulos musicales y sugieren el empleo de la "brillantez" como un descriptor, ya que el término como sinónimo de timbre podría no ser apropiado.

\section{- Scale musicali e valutazioni della brillantezza : effetti di altezza,} direzione e modo della scala

Una forma comune di sinestesia e confronto incrociato non sinestetico dei modi musicali coinvolge un'associazione fra brillantezza visiva e frequenza uditiva, e la forma di tale associazione è stata studiata in osservatori non sinestetici impegnati nella valutazione della brillantezza percepita in scale musicali ascendenti e discendenti di quattro modi (minore naturale, melodico e armonico, e maggiore [includendo sia le scale relative maggiori che quelle parallele]). II modo minore armonico discendente è stato valutato come più cupo rispetto al modo minore naturale/melodico discendente. Scale minori e maggiori ascendenti sono state giudicate più brillanti di quelle maggiori e minori discendenti. Inoltre, tonalità con la nota fondamentale più acuta sono state valutate come più brillanti rispetto a tonalità con la fondamentale più grave. Nelle valutazioni della brillantezza non si sono osservate differenze significative fra i partecipanti musicalmente esperti e quelli musicalmente inesperti. I dati sono coerenti coi risultati raggiunti in precedenza e suggeriscono come ad influenzare la valutazione sulla brillantezza degli stimoli musicali siano aspetti più globali di altezza, distanza fra note successive e profilo melodico (ossia la direzione del movimento delle note), piuttosto che il modo o la tonalità di per sé; tali dati indicano inoltre come la recente adozione del termine "brillantezza" quale indicatore o sinonimo del solo timbro musicale potrebbe non essere appropriata. 
Une forme courante de la synesthésie et de l'évaluation intermodale non synesthésique suppose une association entre luminosité visuelle et fréquence auditive; c'est cette forme d'association qui est étudiée dans la perception non synestésique de la brillance des échelles musicales ascendantes et descendantes de quatre modes (naturel, mélodique, harmonique mineur et majeur ly compris les échelles relatives et parallèles]). Le mode harmonique mineur descendant est perçu comme étant plus sombre que le mode mineur naturel/mélodique descendant. Les modes majeurs ascendants et descendants sont ressentis comme étant plus brillants que les modes mineurs et majeurs descendants. En outre, un mode dont la première note est aiguë est perçu comme étant plus brillant que celui dont la première note est grave. On ne relève pas de différences significatives entre les évaluations des participants, que ceux-ci aient ou non une formation musicale. Ces données corroborent les résultats antérieurs et donnent à penser que l'évaluation de la brillance découle davantage des aspects globaux de la hauteur du son, de la distance entre les notes et de leur contour (autrement dit la trajectoire des notes) que du mode ou de la tonalité en tant que telle. Aussi nous semble-t-il inapproprié, comme on tend à le faire aujourd'hui, d'utiliser le terme "brillance" pour décrire le seul timbre, voire d'en faire son synonyme.

\section{- Tonleitern und Evaluation von Helligkeit: Effekte von Tonhöhe,} Verlauf und Tongeschlecht

Eine bekannte Form synästhetischer und nicht synästhetischer cross-modaler Kombination ist die Assoziation von visueller Helligkeit mit auditiver Frequenz. Diese Art der Assoziation wurde in der vorliegenden Studie an nicht synästhetischen Probanden untersucht, die eine wahrgenommene Helligkeit mit aufsteigenden und absteigenden Tonleitern verglichen. Diese Tonleitern schlossen verschiedene Tongeschlechter ein (reine, melodische und harmonische Moll-Tonleitern und DurTonleitern bzw. verwandte und parallele Dur-Skalen). Die absteigende harmonische Molltonleiter wurde als dunkler bewertet als die absteigende reine und die absteigende melodische Molltonleiter. Aufsteigende Moll- und Durtonleitern wurden als heller bewertet als absteigende Moll- und Durtonleitern. Darüber hinaus wurden Tonarten, die auf einem höheren Ton begannen als heller bewertet als Tonarten, die auf einem tieferem Ton begannen. Zwischen musikalische gebildeten und musikalisch weniger gebildeten Probanden zeigten sich in Bezug auf die Helligkeitsbewertungen keine systematischen Unterschiede. Die Daten bestätigten frühere Ergebnisse und zeigten, dass umfassendere Aspekte der Tonhöhe, Tonabstände zwischen Tönen sowie Melodiekontur (d.h. die Richtung der Tonbewegung) und nicht nur Tongeschlecht oder der spezifische Ton die Bewertung der Helligkeit musikalischer Stimuli beeinflussen. Es zeigte sich auch, dass der Gebrauch des Terminus "Helligkeit“ als eine Beschreibung oder ein Synonym für Klangfarbe eher unpassend ist. 